IZA DP No. 8189

Labor Market Deregulation and Female Employment:

Evidence from a Natural Experiment in Japan

Takao Kato

Naomi Kodama

May 2014 


\title{
Labor Market Deregulation and Female Employment: Evidence from a Natural Experiment in Japan
}

\author{
Takao Kato \\ Colgate University, IZA, CJEB, Columbia Business School, \\ TCER, University of Tokyo and CCP, Aarhus School of Business \\ Naomi Kodama \\ IER, Hitotsubashi University \\ and RIETI
}

Discussion Paper No. 8189

May 2014

IZA

P.O. Box 7240

53072 Bonn

Germany

Phone: +49-228-3894-0
Fax: +49-228-3894-180
E-mail: iza@iza.org

Any opinions expressed here are those of the author(s) and not those of IZA. Research published in this series may include views on policy, but the institute itself takes no institutional policy positions. The IZA research network is committed to the IZA Guiding Principles of Research Integrity.

The Institute for the Study of Labor (IZA) in Bonn is a local and virtual international research center and a place of communication between science, politics and business. IZA is an independent nonprofit organization supported by Deutsche Post Foundation. The center is associated with the University of Bonn and offers a stimulating research environment through its international network, workshops and conferences, data service, project support, research visits and doctoral program. IZA engages in (i) original and internationally competitive research in all fields of labor economics, (ii) development of policy concepts, and (iii) dissemination of research results and concepts to the interested public.

IZA Discussion Papers often represent preliminary work and are circulated to encourage discussion. Citation of such a paper should account for its provisional character. A revised version may be available directly from the author. 


\section{ABSTRACT \\ Labor Market Deregulation and Female Employment: Evidence from a Natural Experiment in Japan*}

This paper provides novel evidence on the causal effect on female employment of labor market deregulation by using the 1985 amendments to the Labor Standards Law (LSL) in Japan as a natural experiment. The original LSL of 1947 prohibited women from working overtime exceeding two hours a day; six hours a week; and 150 hours a year. The 1985 amendments exempted a variety of occupations and industries from such overtime restriction on women. We first define "jobs" using an industry by occupation matrix. For each job (close to 5,000 jobs in total), we carefully identify whether or not it was made exempt from the overtime restriction on women by the 1985 amendments. Applying a difference-in-difference model to census data, we find a statistically significant and economically meaningful impact on female employment of this particular piece of labor market deregulation. Furthermore the 1985 treatment is found to have a lasting and growing impact on female employment. Our finding is consistent with the recent literature that points to the importance of paying particular attention to the issues surrounding working hours when policymakers design public policy to promote female employment.

JEL Classification: J16, J78, J81, J82, J88

Keywords: female employment, labor market deregulation, natural experiment, overtime restriction on women, Labor Standards Law

Corresponding author:

Takao Kato

Department of Economics (Persson 222)

Colgate University

13 Oak Drive

Hamilton, NY 13346

USA

E-mail: tkato@colgate.edu

\footnotetext{
*We would like to thank Ryo Kambayashi and Hitotsubashi University's Large-Scale Data Archiving and Processing Section for aiding our data collection. The research was facilitated by Kato's extended visit to Hitotsubashi University as visiting professor, and Kato is grateful for their hospitality.
} 


\section{Labor Market Deregulation and Female Employment: Evidence from a Natural Experiment in Japan}

\section{Introduction}

This paper provides new evidence on the causal effect on female employment of labor market deregulation by using the 1985 amendments to the Labor Standards Law (LSL) in Japan as a natural experiment. The LSL in Japan was enacted in 1947, and has been a major piece of legislation to regulate the Japanese labor market. The LSL contains a controversial set of protective legislations for women. Perhaps most notable is overtime restriction on women—for female workers overtime is restricted to a maximum of two hours a day; six hours a week; and 150 hours a year (Nakanishi 1983). ${ }^{1}$

The 1985 amendments to the LSL made a variety of industries and occupations (including most professional and supervisory workers as well as many women working in nonmanufacturing industries) exempt from the overtime restriction on women. As such, the significant and large-scale relaxation of the overtime restriction on women in 1985 represents an important example of labor market deregulation.

From the firm's perspective the overtime restriction on women as in the case of the original LSL of 1947 can limit its ability to adjust female labor input in a flexible manner when facing volatile fluctuation in output demand. As a result, the firm may shy away from female employment. Now that such restriction on overtime work is lifted, the firm may start hiring more female workers. However, from the perspective of labor supply, some women may opt to leave

\footnotetext{
${ }^{1}$ The Labor Standards Law also prohibits women from working in night shift (10 p.m. to 5 a.m. with 11 p.m. to 5 a.m. if received an authorization from the Ministry of Labor) except for certain occupations. However, for the remainder of the paper, we focus on the overtime restriction on women, for a significant number of occupations and industries in which many women occupy (e.g., workers in agriculture and hospitality, doctors and nurses, flight attendants) were exempt from the night shift prohibition even in the original Labor Standards Law.
} 
the labor market, fearing that they may be asked to work overtime beyond what used to be deemed a violation of the Labor Standards Law. As such the direction of the effect on female employment of this labor market deregulation is ambiguous theoretically and it is an empirical matter. $^{2}$

Our paper contributes to the literature on public policy and female employment. First, there is a rich literature on affirmative action and its effects on labor market outcomes, such as women's wages and employment (for a literature review prior to 2000, see Holzer and Neumark, 2000, and for more recent works, see for instance , Miller and Segal, 2012, Kurtulus, 2012, Marion, 2011, and Niederle, Segal, and Vesterlund, 2013). Second, some researchers examine the effect on women of minimum wage law (see, for example, Addison, and Ozturk, 2013, Kawaguchi and Yamada, 2007, Neumark and Wascher, 2006, and Connolly and Gregory, 2002)

Third, perhaps the most-closely related literature is a small group of studies that investigate the impact on labor market outcomes for women (such as wages and employment) of the Labor Standards Law (see, for instance, Zveglich and van der Meulen Rodgers, 2003 for Taiwan, Hunt, 1999 for Germany, and Goldin, 1988 and Landes, 1980 for the U.S.). All of these studies examined the impact of regulation - the incidence of protective legislations on women, while we study the impact of deregulation-the relaxation of protective legislations on women. Our study as contrasted to prior studies will shed new light on the issue of symmetric policy effects - whether the introduction of public policy has the same effect (in the opposite direction) as the termination of public policy.

Methodologically most recent studies in the afore-mentioned related literatures tend to use the natural experimental approach to go beyond correlational studies, and identify causal relationships. We follow the current practice in the literature and apply the natural experiment

\footnotetext{
${ }^{2}$ Similar arguments are presented by Zveglich and van der Meulen Rodgers (2003)
} 
framework to the 1985 amendments to Japan's LSL--the relaxation of the overtime restriction on women in Japan.

\section{Empirical Strategy}

Using Japan's Population Census from 1970 to 2010, we first combine industry groups with occupation groups, and create close to 5,000 unique combinations of industry and occupation groups which we call "jobs" henceforth. As such, our unit of observation is job. For each of close to 5,000 jobs, we carefully study the LSL of 1947 as well as the 1985 amendments, and determine whether or not the 1985 amendments made the job exempt from the overtime restriction on women. A group of jobs which were made exempt from the overtime restriction by the 1985 amendments constitute the treatment group. The appropriate control group is a group of jobs which were not made exempt from the overtime restriction by the amendment and thus remained subject to the restriction even after 1985.

To evaluate the effect on female employment of the 1985 amendments, we use published detailed cross-tabulations from Population Census from 1975 to 2010 and estimate the following standard difference-in-difference model:

female $_{i t}=\alpha+\beta$ exempt $_{i t}+\gamma$ totalwork $_{\mathrm{it}}+($ job fixed effects $)+($ year effects $)+\varepsilon_{\mathrm{it}}$

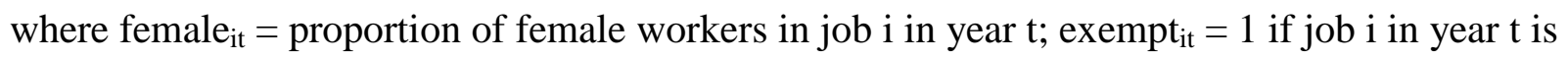
exempt from the LSL's hours restriction on women, zero otherwise; totalwork $\mathrm{k}_{\mathrm{it}}=$ total number of workers (in log) in job i in year $\mathrm{t}$; and $\varepsilon_{\mathrm{it}}=\mathrm{error}$ term. The estimated coefficient on exempt $\mathrm{t}_{\mathrm{t}}$ is of prime interest, and the positive and significant coefficient indicates that labor market deregulation to remove the overtime restriction on women causes female employment to rise. Such a causal interpretation is appropriate thanks to our natural experimental framework. First, 
job fixed effects control for any unobserved inherent job characteristics that can be correlated with female employment. Our key coefficient, $\beta$, is identified by status changes from being not exempt from the overtime restriction to being exempt from it within the same job. As such, inherent job characteristics, be it observed or not, are fully accounted for.

Second, year effects account for any changes that may affect female employment insofar as they affect all jobs. The inclusion of year effects is critical, for there have been a number of other changes in the regulatory environments surrounding female employment over the time period under study. For instance, the enactment of Equal Employment Opportunity Act (EEOA) in 1986, the passage of the 1992 Child Care Leave Act, the 1999 Child Care and Family Care Leave Act, and its amendment in 2005 are all potentially important changes. ${ }^{3}$ To the extent to which they affect all jobs, such changes will be controlled for by year effects. Even if some of those changes do not affect all jobs equally, it is highly unlikely that they affect the same group of jobs as the 1985 amendments. As such, those unobserved changes that may affect female employment will be uncorrelated with exempt $\mathrm{i}_{\mathrm{it}}$ posing little problem.

Though fully accounting for all time-invariant heterogeneity of jobs, job fixed effects do not control for time-varying job-specific shocks, perhaps most notably demand shocks for specific jobs. For instance, those jobs that were made exempt from the overtime restriction on women by the 1985 amendments happened to be those jobs which experienced significant surge in demand at the same time. If that is the case, the estimated coefficient on exempt $t_{i t}$ may be confounded by such time-varying job-specific demand shocks. To control for such demand shocks, we include totalwork $\mathrm{it}_{\mathrm{it}}$ (total number of workers in job i in year $\mathrm{t}$ ) as a control variable.

It is plausible that the 1985 amendments might not have affected female employment

\footnotetext{
${ }^{3}$ For the effects of such subsequent policy changes toward women, see for example, Edwards and Pasquale, 2003, Abe, 2010, Kato, Kawaguchi, and Owan, 2013, and Asai, 2013)
} 
immediately. Instead the treatment effect may appear gradually over time. To explore such a time profile of the treatment effect, we augment Eq. (1) by interaction terms involving each year dummy variable since the 1985 amendments and exempt $t_{i t}$ :

$$
\begin{aligned}
& \text { female }_{i t}=\alpha+\beta \text { exempt }_{i t}+\gamma \text { totalwork }_{i t}+(\text { job fixed effects) }+ \text { (year effects }) \\
& +\delta_{90} \text { year90*exempt } t_{i t}+\delta_{95} \text { year95* } \text { exempt }_{i t}++\delta_{00} \text { year00*exempt }_{\text {it }} \\
& +\delta_{05}{\text { year } 05 * \text { exempt }_{\mathrm{it}}}+\delta_{10} \text { year } 10 * \text { exempt }_{\mathrm{it}}+\varepsilon_{\mathrm{it}}
\end{aligned}
$$

The estimated coefficients on such interaction terms indicate the time profile of the effect on female employment of the 1985 amendments.

Lastly, there was another change in the overtime restriction on women in the LSL in 1997. However, we believe that the 1997 change was substantially less important as compared to the 1985 change since most jobs that were affected by the 1997 change tend to be less important for women. Nonetheless we repeated the same analysis, excluding data for all years after the 1997 change (2000, 2005 and 2010). As shown below, reassuringly we find little change in our main results.

\section{$\underline{\text { III. Results }}$}

Table 1 presents the fixed effect estimates of Eq. (1) and Eq. (2). Regressions are weighted with the total number of population workers. As shown below, the key results change little in un-weighted regressions.

The estimated coefficient on exempt $t_{i t}$ in our baseline model in Column (1) is positive and significant at the 1 percent level, pointing to the positive effect on female employment of the removal of the overtime restriction on women by the 1985 amendments. The size of the estimated coefficient suggests that the 1985 amendments result in a 3.6 percentage-point increase 
in the proportion of female employment. Considering that the average proportion of female employment in 1985 was 35 percent, the magnitude of the effect of the 1985 amendments is neither trivial nor implausible. The estimated coefficient on totalwork $\mathrm{it}_{\mathrm{i}}$ is positive and significant at the 5 percent level, suggesting that stronger overall labor demand helps female employment disproportionately.

The fixed effect estimates of Eq. (2) are also shown in Column (2) of the table. When we allow the effect on female employment of the 1985 amendments to linger over time by augmenting Eq. (1) with interaction terms involving year dummy variables and the 1985 treatment dummy variable, an intriguing time profile of the treatment effect is revealed. On the one hand, the estimated coefficient on the 1985 amendments itself is now quite small and no longer statistically significant even at the 10 percent level, suggesting that there is little immediate impact on female employment of the 1985 amendments. On the other hand, the estimated coefficients on all interaction terms involving the 1985 treatment and all year dummy variables since the 1985 amendment are positive and statistically significant at least at the 5 percent level. Furthermore, the size of the coefficient grows as time passes. The estimated coefficients on such interaction terms suggest that the 1985 treatment might have had a lasting impact on female employment.

Table 2 summarizes the results of our robustness checks. First, our key results—-the positive and significant coefficients on exempt ${ }_{i t}$ in Eq. (1) and the positive, significant, and growing coefficients on the interaction terms involving exempt $t_{i t}$ and the year dummy variables in Eq. (2) turn out to be insensitive to whether or not we weight regressions (although the size of the effect tends to be smaller in un-weighted regressions). Second, when we exclude all data 
after the 1997 revision and focus only on the 1987 amendments, we still find the estimated coefficient on exempt $t_{i t}$ to be positive and statistically significant at the 1 percent level.

Third, it is possible that exempt $t_{i t}$ and the interaction terms involving exempt $t_{i t}$ and the year dummy variables are picking up industry-specific time trends during the period under study. To account for such industry-specific time trends, we add separate linear time trends for each of 85 industry classifications to the right-hand side of Eq. (1) and Eq. (2). As shown in the last row of Table 2, our key results are again found to be robust to the inclusion of such industry-specific time trends.

Fourth, a threat to identification would arise if our treatment and control jobs had experienced differential trends in female employment prior to the 1985 amendments. This would cause our regression to erroneously identify a policy effect that was instead due to differences in pre-treatment trend patterns. Fortunately, this limitation appears to afflict our estimates little. For the treatment group and the control group separately, we first calculate the average proportion of female employment for each year over the entire time period under study, including both preand post-1985 amendments periods. We then show those two time-series of the average proportion of female employment for the treatment group and the control group in Figure 1. Reassuringly the figure shows no indication that our difference-in-difference estimates of the treatment effect on female employment is capturing the difference in the pre-treatment trends between the treatment and control groups. In fact, the figure points to an upward trend for the control group prior to 1985 while no such upward trend for the treatment group (a mildly downward trend, indeed). Such pre-treatment trend pattern was then reserved following the treatment (the 1985 amendments). In other words, the figure suggests that the difference in the pre-treatment trends between the treatment and control groups is working against finding the 
positive and significant treatment effect. As such, the consideration of the pre-treatment trends will strengthen rather than weaken our conclusion-the positive and significant treatment effect on female employment.

Finally, the possible endogeneity of the treatment variable, exempt $t_{i t}$ can be a threat to our empirical strategy as in the case of many other natural experimental studies. In other words, if some omitted variable is correlated with this treatment variable AND female employment (female $e_{i t}$ ), the estimated coefficient of our primary interest, $\beta$ will be biased. As discussed above, there are a number of possible time-varying factors that affect female employment (e.g., other changes in the regulatory environments regarding female employment). Nonetheless most of those factors affect all industries and occupations equally and hence are captured by the year effects. Even if they affect only a subset of industries and occupations, it is highly unlikely that they affect a specific group of industry*occupation combinations (or jobs) that happen to correspond to our treatment jobs. For instance, on our reading of the literature, there is no legislative and institutional changes concerning female employment during the time period under study that affected the same set of jobs as the 1985 amendments did.

\section{$\underline{\text { IV. Concluding remarks }}$}

Asai (2013)’s carefully-crafted difference-in-difference study uncovers the inefficacy of Japanese government's legislative efforts to reduce the cost of parental leave. Our finding of the efficacy of Japanese government’s legislative effort to remove legal protection for women regarding overtime work presents an intriguing contrast. We believe that a key difference between the two studies lie in the nature of public policy each study focuses on. The 1985 amendments to the LSL were aimed at allowing female workers to work long hours. The recent 
literature on gender gaps in the labor market points to the importance of the female employee's willingness and ability to work long hours for their career success (see, for instance, Bertrand, Goldin and Katz, 2010, Cha and Weeden, 2013, Kato, Kawaguchi and Owan, 2013, Bardsley and Sherstyuk , 2006, and Gicheva 2013). To this end, our study can be viewed as yet another study that stresses the importance for policy makers to pay particular attention to the issues surrounding working hours in designing policy instruments to promote female employment. 


\section{References}

Abe, Y., 2010. Equal Employment Opportunity Law and the Gender Wage Gap in Japan: A Cohort Analysis. Journal of Asian Economics 21, 142-155.

Addison, J.T., O.D. Ozturk, 2012. Minimum Wages, Labor Market Institutions, and Female Employment: A Cross-Country Analysis. Industrial and Labor Relations Review 65, 779809.

Asai, Y., 2013. Parental Leave Reforms and the Employment of New Mothers: Quasiexperimental Evidence from Japan. (Paper Presented at the SOLE meeting).

Bardsley, P., K. Sherstyuk, 2006. Rat Races and Glass Ceilings. B.E. Journal of Theoretical Economics: Topics in Theoretical Economics 6, 1-35.

Bertrand, M., C. Goldin, L.F. Katz, 2010. Dynamics of the Gender Gap for Young Professionals in the Financial and Corporate Sectors. American Economic Journal: Applied Economics 2, 228-255.

Cha, Y., K.A. Weeden, 2013. Overwork and the Slow Convergence in the Gender Gap in Wages. American Sociological Review (forthcoming).

Connolly, S., M. Gregory, 2002. The National Minimum Wage and Hours of Work: Implications for Low Paid Women. Oxford Bulletin of Economics and Statistics 64, 607-631.

Edwards, L.N., M.K. Pasquale, 2003. Women's Higher Education in Japan: Family Background, Economic Factors, and the Equal Employment Opportunity Law. Journal of the Japanese and International Economies 17, 1-32.

Gicheva, D., 2013. Working Long Hours and Early Career Outcomes in the High-End Labor Market. Journal of Labor Economics 31, 785-824.

Goldin, C., 1988. Maximum Hours Legislation and Female Employment: A Reassessment. Journal of Political Economy 96, 189-205.

Holzer, H., D. Neumark, 2000. Assessing Affirmative Action. Journal of Economic Literature 38, 483-568.

Hunt, J., 1999. Has Work-Sharing Worked in Germany? Quarterly Journal of Economics 114, 117-148.

Kato, T., D. Kawaguchi, H. Owan, 2013. Dynamics of the Gender Gap in the Workplace: An Econometric Case Study of a Large Japanese Firm, Paper presented at the NBER Japan Project meeting. (Tokyo).

Kawaguchi, D., K. Yamada, 2007. The Impact of the Minimum Wage on Female Employment in Japan. Contemporary Economic Policy 25, 107-118.

Kurtulus, F.A., 2012. Affirmative Action and the Occupational Advancement of Minorities and Women during 1973-2003. Industrial Relations 51, 213-246.

Landes, E.M., 1980. The Effect of State Maximum-Hours Laws on the Employment of Women in 1920. Journal of Political Economy 88, 476-494.

Marion, J., 2011. Affirmative Action and the Utilization of Minority- and Women-Owned Businesses in Highway Procurement. Economic Inquiry 49, 899-915.

Miller, A.R., C. Segal, 2012. Does Temporary Affirmative Action Produce Persistent Effects? A Study of Black and Female Employment in Law Enforcement. Review of Economics and Statistics 94, 1107-1125.

Nakanishi, T., 1983. Equality or Protection? Protective Legislation for Women in Japan. International Labour Review 122, 609-621.

Neumark, D., W. Wascher, 2004. Minimum Wages, Labor Market Institutions, and Youth 
Employment: A Cross-National Analysis. Industrial and Labor Relations Review 57, 223-248.

Niederle, M., C. Segal, L. Vesterlund, 2013. How Costly Is Diversity? Affirmative Action in Light of Gender Differences in Competitiveness. Management Science 59, 1-16.

Zveglich, J.E., Jr., Y.v.d.M. Rodgers, 2003. The Impact of Protective Measures for Female Workers. Journal of Labor Economics 21, 533-555. 
Table 1 The Effect on Female Employment of the 1985 Amendments to the Labor Standards Law: Dependent variable $=$ female $_{\text {it }}$

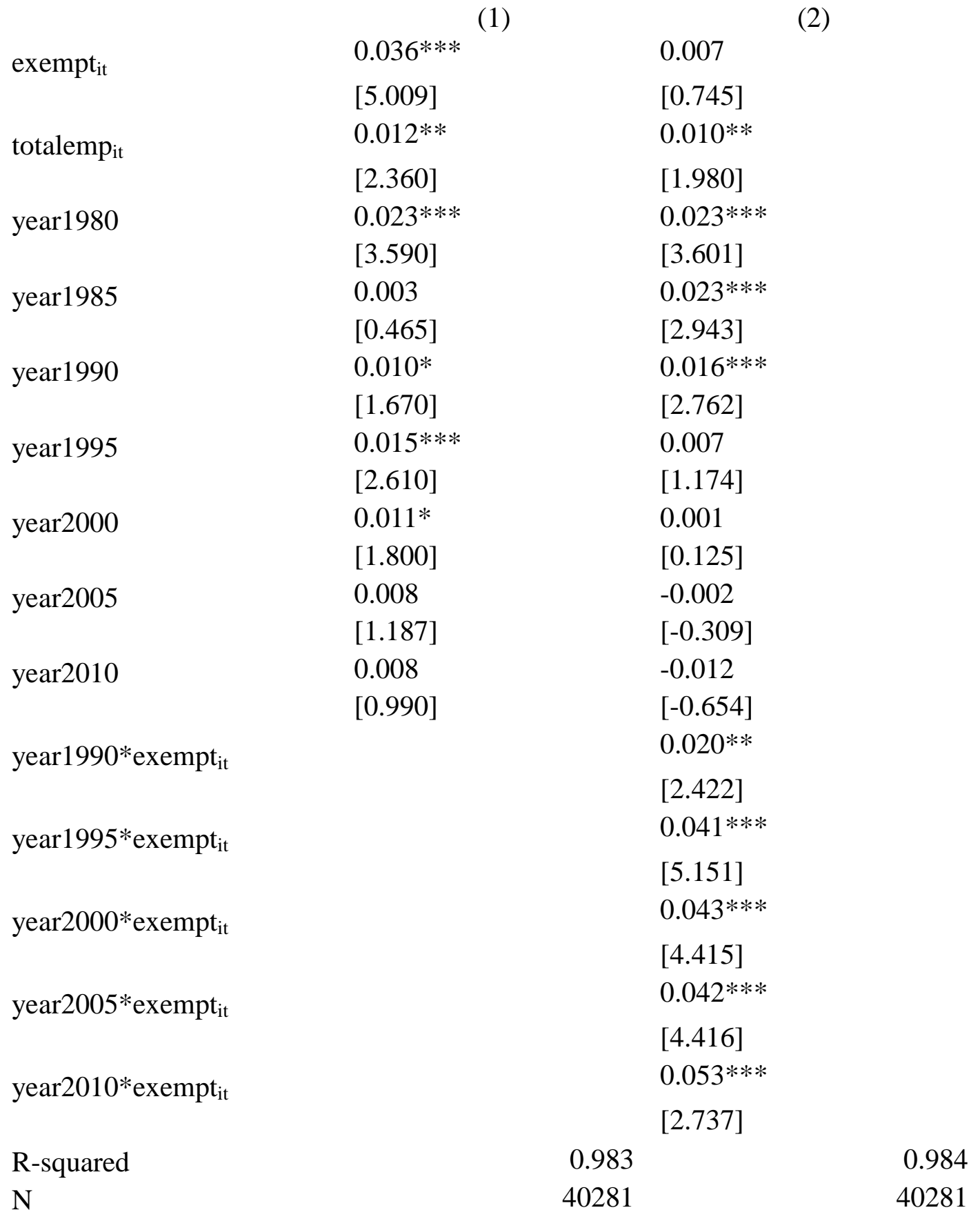

Source: Population Census, Japan Statistical Bureau for 1975, 1980, 1985, 1990, 1995, 2000, 2005, and 2010.

Notes: All models include individual job fixed effects. Standard errors are clustered at the individual job level. Regressions are weighted with the total number of population workers. Absolute value of t-statistics in parentheses.

Significance level: *** 1 percent $* * 5$ percent $* 10$ percent 
Table 2 Robustness Checks: Dependent variable $=$ female $_{i t}$

\begin{tabular}{|c|c|c|c|c|c|c|}
\hline & (1) & & & (2) & & \\
\hline & exempt $t_{\text {t }}$ & $\begin{array}{c}\text { year1990* } \\
\text { exempt }_{\text {t }}\end{array}$ & $\begin{array}{c}\text { year1995* } \\
\text { exempt }_{\text {tit }}\end{array}$ & $\begin{array}{c}\text { Year2000* } \\
\text { exempt }_{\text {it }}\end{array}$ & $\begin{array}{c}\text { Year2005* } \\
\text { exempt }_{\text {it }}\end{array}$ & $\begin{array}{l}\text { Year2005* } \\
\text { exempt }_{\text {t. }}\end{array}$ \\
\hline From Table 1 & $0.036^{* * *}$ & $0.020^{* *}$ & $0.041^{* * *}$ & $0.043^{* * *}$ & $0.042^{* * *}$ & $0.053^{* * *}$ \\
\hline & [5.009] & [2.422] & [5.151] & [4.415] & [4.416] & [2.737] \\
\hline & $0.016^{* * *}$ & 0.009 & $0.021^{* * *}$ & $0.033 * * *$ & $0.035^{* * *}$ & $0.051^{* * *}$ \\
\hline Un-weighted & [3.768] & [1.604] & [3.551] & [5.651] & {$[5.560]$} & [5.732] \\
\hline $\begin{array}{l}\text { Exclude data after } \\
1997 \text { revision }\end{array}$ & $\begin{array}{l}0.025 * * * \\
{[4.272]}\end{array}$ & & & & & \\
\hline 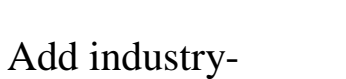 & $0.017^{* *}$ & $0.018^{* *}$ & $0.037 * * *$ & $0.038 * * *$ & $0.041 * * *$ & $0.056^{* * *}$ \\
\hline pecific time trends & [2.292] & [2.491] & [5.245] & [4.412] & [4.312] & [3.337] \\
\hline
\end{tabular}

Source: Population Census, Japan Statistical Bureau for 1975, 1980, 1985, 1990, 1995, 2000, 2005, and 2010.

Notes: All models include individual job fixed effects. Standard errors are clustered at the individual job level. Absolute value of t-statistics in parentheses.

Significance level: *** 1 percent $* * 5$ percent $* 10$ percent 
Figure 1 Proportion of female workers: treatment vs. control

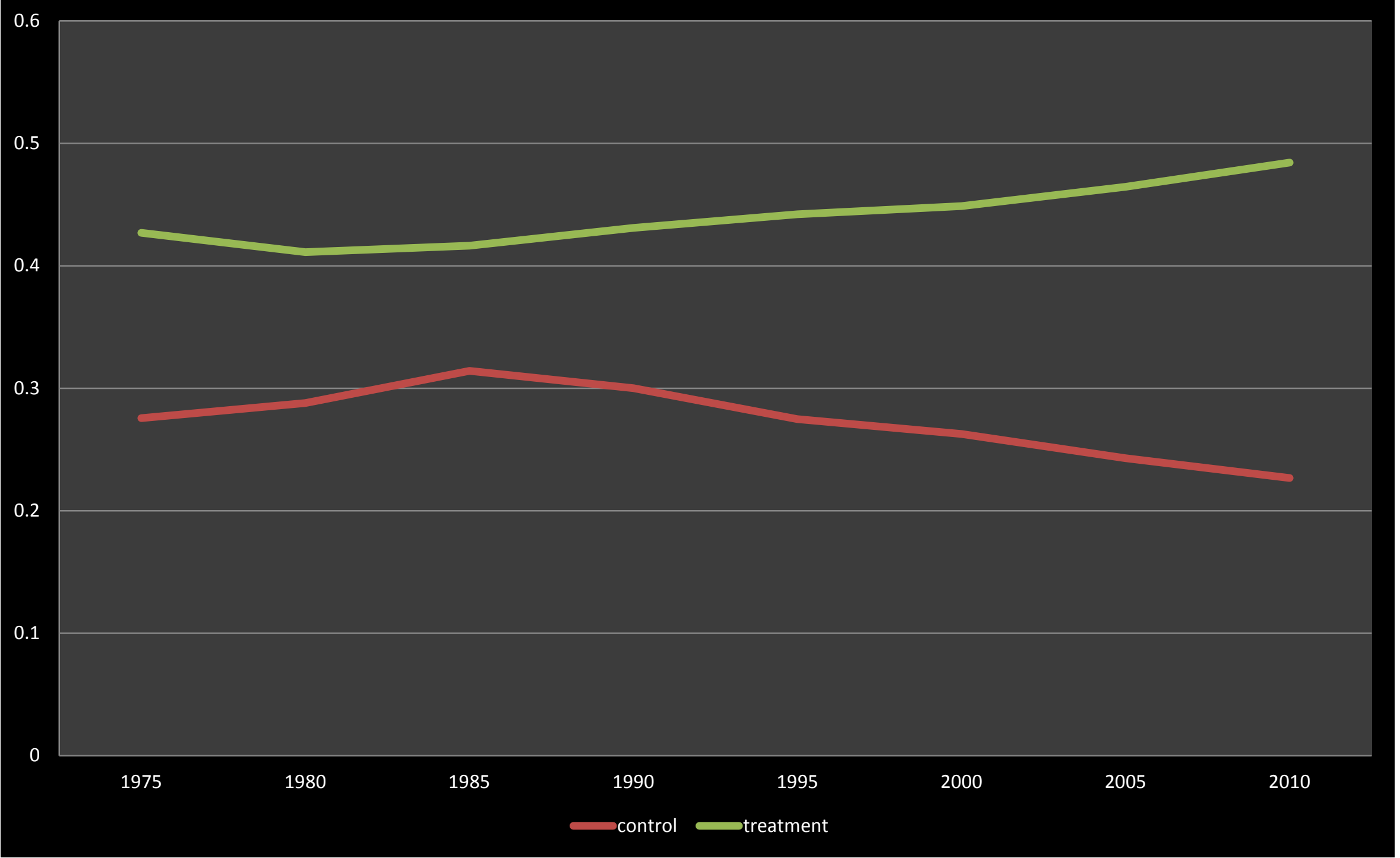

